\title{
Prevention of spinal cord injuries in an Australian study (New South Wales)
}

\author{
J D Yeo AO
}

Medical Director, Moorong Spinal Unit, Royal Rehabilitation Centre, Ryde, NSW, Australia.

The Spinal Awareness and Prevention Programme presented through the Royal North Shore Hospital and the Royal Rehabilitation Centre, in Sydney, NSW, Australia has grown considerably since 1982. Ten years later it is pleasing to report that the programme has grown in response to public demand and requires a full time coordinator, secretary and five disabled lecturers (part time). This prevention message now reaches over 100,000 school students throughout New South Wales every year as well as the community in general through media advertising. Over the last 5 years the annual incidence of spinal cord injury has dropped by $20 \%$ in New South Wales for motor vehicle accidents, contact sport and water related accidents.

The 'lifetime' costs for paraplegia approach AUS $\$ 1,000,000$ and for quadriplegia AUS $\$ 2,000,000$. The reduction of serious spinal injuries means that at least 20 families in this State, with a population of nearly 6 million, will not this year have to face the tragedy and enormous challenge of permanent paralysis.

There is now commitment to the promotion of prevention of spinal cord injuries. The annual cost of this programme to each individual in the community is less than 10 cents.

Keywords: spinal cord injuries; etiology; prevention; education.

\section{Introduction}

Over the last 10 years an Awareness and Prevention Programme has been promoted from the spinal injuries units at the Royal North Shore Hospital, Sydney and at the Royal Rehabilitation Centre, Ryde. Both these specialised units are in the state of New South Wales and, with Prince Henry Hospital, help to provide a comprehensive treatment programme for patients with spinal cord injury. Between 100 and 150 patients with significant spinal cord injury are treated each year.

In conjuction with the care of these recently injured patients followed by the specialised rehabilitation programmes, a community education programme has been developed and promoted throughout the state of New South Wales and the Australian Capital Territory reaching up to 100,000 school children per annum at primary and secondary school levels. ${ }^{1}$ The programme also reaches adolescent groups and a num- ber of adult groups such as Rotary. The population of New South Wales now approaches one third of the total population of Australia (17 million).

The need for this Awareness and Prevention Programme in the community was highlighted by the rapid increase in the number of patients admitted to spinal units in New South Wales in the late 1970s. Motor vehicle accidents, water related injuries and injuries in contact sport were identified as the main causes for increased admissions.

\section{Aims}

The aims of the programme were:

1 to identify the incidence of spinal cord injury in New South Wales;

2 to identify the etiology of spinal cord injury in the community;

3 to identify the factors which appear to influence the incidence of spinal cord injury; 
4 to design and develop programmes aimed at educating the community both generally and more specifically in schools.

\section{Methods}

An actuary, ${ }^{2}$ and two scientific officers were contracted to collect the data at the two spinal units in Sydney (Royal North Shore Hospital and Prince Henry Hospital). The database was primarily collected from details of patients recently admitted with significant loss of motor power and sensation associated with spinal cord injury. Details were obtained from the hospital notes identifying the etiology of the injury and the causes categorised under the following main headings:

motor car accidents
motor bike accidents
contact sport (Rugby Union and
$\quad$ Rugby League)
sporting injuries
water related injuries
falls
other (eg gunshot wounds).

Patients were also interviewed and where possible the factors contributing to spinal cord injury were identified and, where available, helmets were examined.

An initial study involved 20 consecutive patients, who had been involved in motor bike accidents admitted to the spinal unit at Royal North Shore Hospital, Sydney.

An expanded study then involved interviewing 130 motor cycle riders who were admitted to the spinal units in Australia.

Forty-five footballers were interviewed and each player was asked to identify the position of the head, neck, body and limbs at the moment of impact.

The awareness and prevention team was then formed with a coordinator and five lecturers who themselves were in wheelchairs. Fund raising was necessary to support the programme through the media, which included television, radio, cinema advertising and advertising on public transport. The total cost of the Awarenes and Prevention Programme now approaches AUS $\$ 430,000$ per annum.

\section{Results}

1 Following the publication of our previous report, ${ }^{3}$ there has been a reduction of $20 \%$ over the last 5 years in the absolute numbers of patients admitted to specialised spinal units in New South Wales (Table I). If these numbers are averaged in 3-year periods, this reduction would be reduced to $17 \%$. The Roads and Traffic Authority of New South Wales has recorded reduction in deaths from road trauma. A total of 652 persons were killed on New South Wales roads during 1992 which is the lowest annual figure since $1950 .^{4}$

The statistics collected identify a reduction in the number of spinal cord injuries from motor car accidents, water related accidents and from contact sport such as Rugby Union and Rugby League football. (Figs $1 \& 2$ ).

2 Motor cyclists were found to be more prone to cervical spinal cord injury when wearing the open face helmet rather than the full face helmet with an 'apron'.5

3 Studying how neck injury occurred in individual football players identified the significant contribution to spinal cord injury of flexion and rotation of the head and neck on the fixed shoulders. Frequently the cervical spinal cord injury occurred before the ball was even placed into the Rugby Union scrum (the maul ruck play was also dangerous). 6 'Spear' tackles, which are illegal, were a more frequent source of injury in the Rugby League code of fooball. ${ }^{7}$

Table I Traumatic SCI injury admissions to Royal North Shore and Prince Henry Hospitals (NSW) in relation to population (NSW)

\begin{tabular}{rrcc}
\hline Year & SCI & $\begin{array}{c}\text { Population } \\
\text { (million) }\end{array}$ & $\begin{array}{c}\text { Incidence rate } \\
\text { (per million) }\end{array}$ \\
\hline 1986 & 111 & 5.79 & 19.2 \\
1987 & 127 & 5.87 & 21.6 \\
1988 & 121 & 5.97 & 20.3 \\
1989 & 112 & 6.04 & 18.5 \\
1990 & 115 & 6.11 & 18.8 \\
1991 & 89 & 6.17 & 14.4 \\
1992 & 97 & 6.23 & 15.6 \\
\hline
\end{tabular}




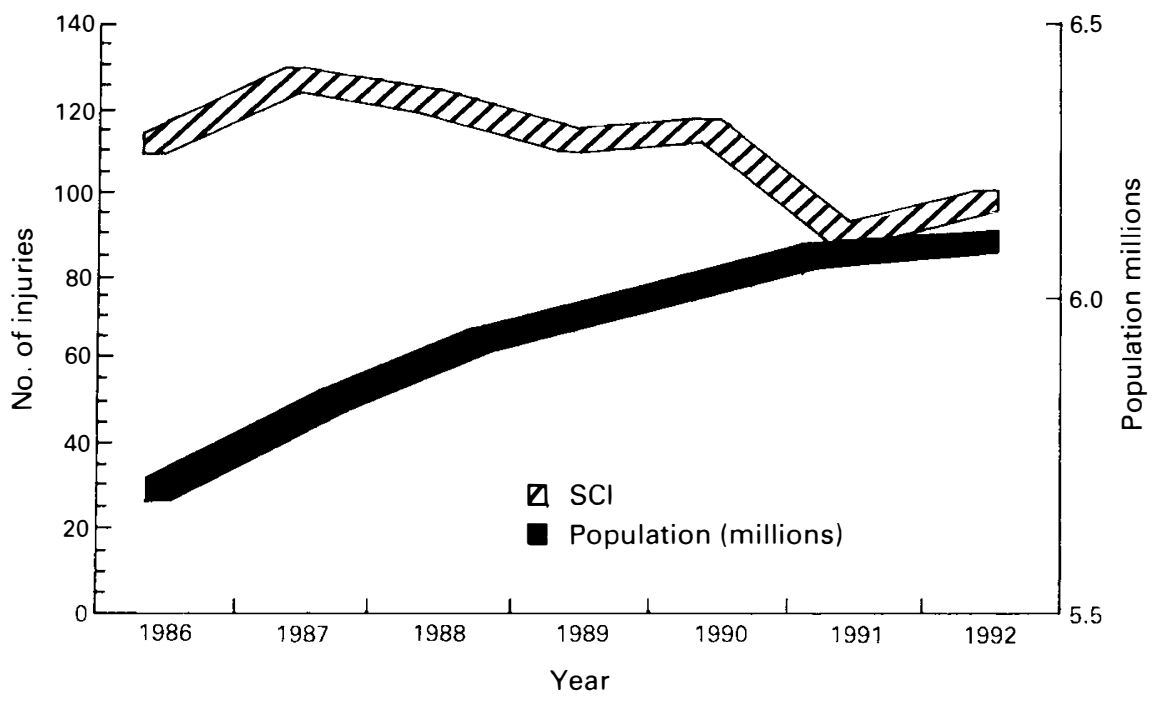

Figure 1 Trend in the incidence of spinal cord injuries in New South Wales between 1986 and 1992, compared with population.

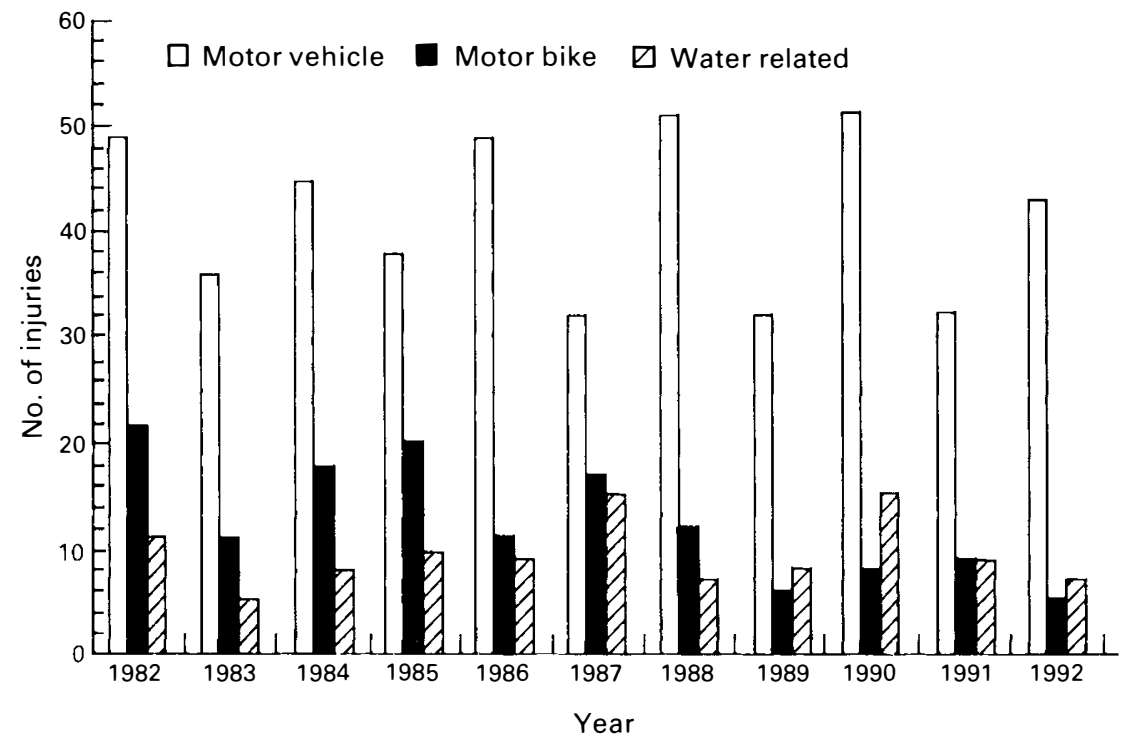

Figure 2 Incidence and etiology of traumatic spinal cord injury (NSW) over an 11-year period (1982-1992).

\section{Discussion}

The reduction in the incidence of spinal cord injury in Australia was anticipated by those involved in primary prevention. ${ }^{8}$ This reduction can now be identified with the introduction of compulsory seat belts, random breath testing, the compulsory wearing of helmets for motor cyclists and education programmes, including the Awareness and Prevention Programme promoted from the Spinal Injury Unit, Royal Rehabilitation Centre, Ryde (Fig 3). 


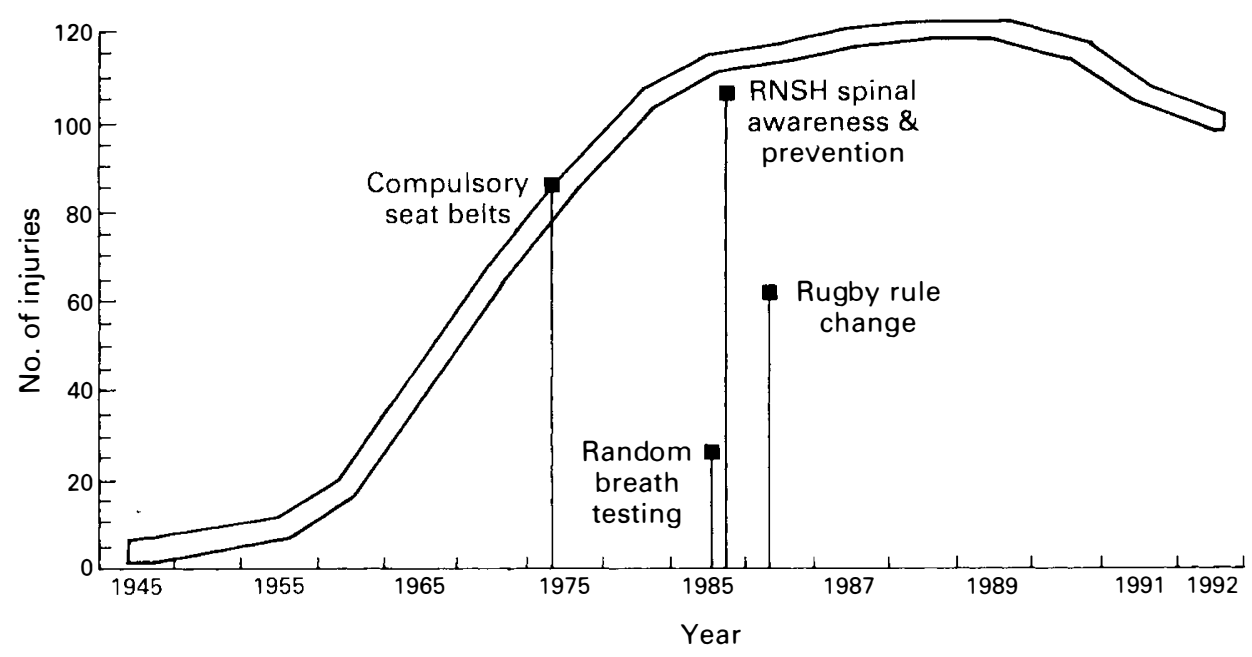

Figure 3 Incidence of traumatic spinal cord injury in NSW and introduction of education programmes and preventative measures (1945-1992).

This preventative programme was first introduced to educate children in both primary and secondary schools (between the ages of 10 and 18) and to appeal to these children to carry the message of 'Enjoying life and doing it safely!' to adult and sibling members of the family and hopefully beyond.

Motor cyclists have been encouraged to wear not only a helmet approved by the Standards Association of Australia but preferably the full faced type helmet which appears to transmit the impact away from the head and neck to the shoulders, thus offering more protection to the cervical spinal cord. The New South Wales Police Department has provided an excellent example for the community to follow. Having identified why players are admitted from the football field with serious spinal cord injuries, authorities in both codes of football have acted responsibly and reinforced the following: playing to the rules; preparing the player for the position for which he is chosen; and encouraging players to report injury, allowing appropriate examination and recovery before reentering the field of play.

In the State of New South Wales the costs of spinal cord injury may reach AUS $\$ 1,000,000$ for a paraplegic casualty aged 25 and $\$ 2,000,000$ for a quadriplegic casualty and these costs will increase. ${ }^{1}$ The expected incidence of spinal injuries now approach 100 patients per year and $50 \%$ of those patients will be quadriplegic and the remainder paraplegic or paraparetic. The cost to the community will be of the order of $\$ 150,000,000$ of 'diverted' funds in one year. The value of this prevention programme, costing less than $\$ 500,000$, cannot not be overemphasised.

\section{Conclusions}

The Education and Prevention Programme as presented from the spinal units in the State of New South Wales demonstrates a cost effectiveness which demands the attention of governments around the world.

\section{References}

1 Yeo JD (1989) Staffing the spinal injuries unit. Paraplegia 27: 150 (abstract).

2 Walsh J (1988) Costs of spinal cord injury in Australia. Paraplegia 26: 386-388 (abstract).

3 Yeo JD, Walsh J (1987) Prevention of spinal cord injuries in Australia. Paraplegia 25: 221-224. 
4 Road and Traffic Authority (December 1992) Monthly Bulletin of Preliminary Traffic Accident Data: $i$.

5 Yeo JD (1979) Five year review of spinal cord injuries in motor cyclists. Med J Aust 2: 381.

6 Silver JR (1987) Spinal injuries as a result of sporting accidents. Paraplegia 25: 16-17.

7 Vanderfield JR (1987) Spinal injuries in rugby football. Paraplegia 25: 410 (abstract).

8 Bedbrook G (1992) Fifty years on fundamentals in spinal cord injury care are still important. Paraplegia 30: $10-13$. 